\title{
Practice Report: Student Health Ambassadors at Residential Campuses Contribute to Safer Campus Living and Learning During the COVID-19 Pandemic
}

\author{
Amy Joy Lanou \\ University of North Carolina Asheville \\ Jordan Perry \\ University of North Carolina Asheville \\ Lane Graves Perry, III \\ Western Carolina University \\ Brian Garland \\ Western Carolina University
}

\author{
Kari Hunt \\ Mars Hill University
}

Kol Gold-Leighton

Mountain Area Health Education Center (MAHEC)

\begin{abstract}
In summer 2020 six residential institutions of higher education (IHE) and the Mountain Area Health Education Center (MAHEC) in Western North Carolina chose a collaborative approach to mitigating COVID-19 infection rates on campus. This approach shares the practices and successes of this concerted effort with a focus on a large public, medium public, and small private IHE. The campuses promoted a healthy and safe culture through a rigorous and transformational learning experience and focused on engaging Student Health Ambassadors (SHAs) in applying the Diffusion of Innovations model to peer-topeer gain-framed messaging for health. Three institutions' programs are presented and cross-case analysis is used to illuminate transferable promising practices. Promising transferable practices across the schools include: selecting the right students, strong institutional support, the three Ps (positive, proactive and prevention-focused), building leadership skills, and peer-led campus culture change. Transferable insights from the practices at three campuses focused on the role and impact of peer-to-peer student health ambassadors on campus to mitigate the spread of COVID-19.
\end{abstract}

Keywords: health behavior, health promotion, peer education, college student health, COVID-19 


\section{BACKGROUND}

In summer 2020, concerns about the spread of COVID-19 infection precipitated the need for a rapid shift in health and safety related behaviors on college campuses as students returned to live and study in the fall. The focus of college reopening efforts was to avoid or reduce the transmission of COVID-19 infection and to mitigate the risk of severe illness and death among those at highest risk (Walke, 2020). Keeping students safely learning and living on campus was predicted to reduce negative impacts on student mental and emotional health, enrollment decreases, and community wide economic concerns. Campuses employed a wide variety of prevention, screening, testing, quarantine and isolation practices. Public health organizations including the Centers for Disease Control and Prevention (CDC) and state health departments provided regularly updated guidance to institutions of higher education (IHE; CIDRAP, 2020).

In a September 2020 commentary in JAMA, CDC-affiliated authors wrote, "A model response - both in planning for and responding to outbreaks - will involve a close partnership between communities and universities to join forces to reduce SARS-CoV-2 transmission" (Walke, 2020, p. 1728). In Western North Carolina (WNC), a group of six residential IHEs chose a collaborative approach to mitigating COVID-19 infection rates, promoting a healthy campus culture, and continuing to provide a rigorous and transformational learning experience. Students along with other campus stakeholders had an integral role in creating a campus environment conducive to learning in the context of a pandemic and the IHEs worked closely with their county health departments and the Mountain Area Health Education Center (MAHEC), an organization committed to improving health in WNC. This collaborative approach focused on engaging SHAs using a peer-to-peer education model, the diffusion of innovative, student-driven ideas, and positive messaging and support rather than "scare tactics" and enforcement.

Peer-to-peer education has been used successfully to shift behaviors on university campuses. A longitudinal evaluation by White et al, (2009) demonstrated that peer health educators have a healthpromoting impact on the alcohol consumption, drug use, and dietary choices of their peers. In a peer-topeer program pairing international and domestic students for 6 weeks, the impact of peer education influenced healthy behaviors and promoted cultural competence (Yan, 2014). In allowing students to help create a culture of health, their own promotion programming is integral as they hold similar values and general temperaments, which allows peer educators to be successful role models during and after school (Brack, 2008).

\section{Diffusion of Innovations}

Students initiating and influencing peer-to-peer campus culture change creates greater buy-in from more reluctant students. Rogers (2003) suggests that in any given population or sector, ideas move through distinct segments codified as innovators $(2.5 \%)$, early adopters $(13.5 \%)$, early majority (34\%), late majority (34\%), and laggards (16\%). As noted, each segment has a specific rate of adoption associated with the idea moving through the population. For example, a public health campaign to slow the spread of COVID-19 on campus that calls for residential students to wear (an approved mask or face covering), wait (physically distance) and wash (sanitize hands properly) would start with a small group of innovators and move into adoption by early adopters, representing $\sim 16 \%$ of the population. As $16 \%$ is insufficient to meet a public health campaign goal, a strategy to reach the early majority $(34 \%)$ would be needed. In an expansion of Rogers' theory, O'Steen and Author (2012) describe the diffusion of an idea from a select few to the wider many. They note that population segment adoption can occur organically or be human-made/informed. Despite current conditions (global pandemic) and the human-made response (mass public health campaign to slow COVID-19 spread), Rogers notes "getting a new idea adopted, even when it has obvious advantages is often very difficult" (2003, p. 1).

\section{Positive Reinforcement and a Gain-Framing Approach}

Numerous studies have shown that gain-framing or positive messaging in efforts to shape health behaviors is more effective than loss-framing or scare tactics. A meta-analysis of 94 papers that compared the persuasive impact of loss- and gain-framed messages on health behaviors showed that gain-framed 
messages were significantly more likely to result in prevention behaviors (Gallagher, 2011). In addition, the IHEs in this collaboration avoided putting SHAs in an enforcement role, as collective experience in peer education and experts in higher education (Levy, 2020) concur that program success is most likely to occur with a positive, proactive, and prevention-focused approach rather than a reactive or enforcementfocused approach. In fact, some experts suggested early on in the pandemic that "scolding and punishing students" may decrease compliance with testing and contact tracing. Simply put, the SHAs' role on the six campuses is to proactively role model and positively support other students (St. Amour, 2020). In doing so, SHAs function as peer educators and culture shifters and can potentially avoid the adverse outcomes associated with this pandemic and engender a culture of wellness and care among their peers.

The purpose of this report is to share the practices and successes of this effort by six IHEs in WNC with a focus on the programs at one small private university (Mars Hill University or MHU), one large public (Western Carolina University or WCU), and one medium public (University of North Carolina - Asheville or UNCA).

\section{METHODS}

\section{WNC Collaboration \& Program Overview}

The collaboration among the six IHEs was initiated by their Chancellors and Presidents who began meeting regularly with MAHEC leadership to strategize for a safe reopening in fall 2020. The SHA program began to take shape as funding for COVID-19 response-related research became available through the NC Policy Collaboratory. UNCA University's Chancellor, Author, and the CEO and the Chair of Public and Community Health at MAHEC applied for and received funds to support the programs. MAHEC leaders contributed funding for the 4 private institutions (MHU, Warren Wilson College [WWC], Brevard College $[\mathrm{BC}]$, and Montreat College [MC]) to support the rapid development and implementation of the SHA program. A project manager was also hired by MAHEC to coordinate the SHA program across the schools (Author). Each campus identified IHE leads for the work (Authors).

In addition, MAHEC provided ongoing technical assistance and clinical consultation to IHE leadership, faculty, and staff throughout the fall semester using the ECHO virtual platform. Scheduled as needed, these hour-long sessions addressed topics such as public health guidance, infection trends and dashboard developments, testing news and protocols, isolation and quarantine protocols, racial equity in COVID-19 response, risk factors for severe illness and vaccination development progress. Weekly cross-institution virtual meetings were also held for the COVID-19 administrative, clinical, and SHA leads from each IHE which provided opportunities for idea sharing, education, and cross-campus communication.

The collective goal of this project was to develop an SHA initiative at each IHE to work with staff and faculty to engage the campus community in responding to COVID-19 and rapidly adopt safe, evidencebased practices that support effective COVID-19 prevention and mitigation. These efforts were designed to complement and support other campus stakeholders' efforts to prepare for safe return of students to campus. All SHAs were to be paid a competitive rate of $\$ 12$ an hour (NC's minimum wage is $\$ 7.25$ an hour). While recruiting volunteers to do this work may have been possible, leads felt strongly about paying SHAs to ensure equity and to elevate the importance of this role.

Differences in IHE calendars and funding receipt dates required asynchronous hiring and training of SHAs. Campuses recruited and hired SHAs independently using a common job description modified to meet their needs. In July, a team of UNCA and MAHEC staff prepared a student-centered training for the incoming SHAs (Author). The curriculum covered the role of the ambassadors, COVID-19 basics, state, local, and campus policies, confidentiality, self-care, supporting peers, evaluation of health information, communication skills, and bystander intervention including role-playing scenarios. On August 5th and 6th, 45 UNCA students (including 10 Peers Educating Peers and Advancing Health [PEPAH] interns, an established campus volunteer peer educator program) were trained using the developed eight-hour curriculum. With support from WCU leaders and WCU faculty who led a summer Pandemic Preparedness Course, WCU leaders trained 21 Catamounts Care (the name for WCU's COVID-19 public health campaign) Student Health Ambassadors on August 21st. On August 28th, MAHEC, UNCA, and WCU 
leaders facilitated a SHA training designed for the newly hired SHAs at the four private IHEs: seven from $\mathrm{BC}$, five from $\mathrm{MHU}$, nine from $\mathrm{MC}$, and six from WWC.

After training, UNCA SHAs met twice weekly to develop peer-to-peer communication strategies and address specific content in smaller teams. All other IHE teams met weekly for ongoing training and support and to plan their peer-to-peer communication strategies. All 93 SHAs wore distinguishing t-shirts and/or ID badges while engaged in peer education and support activities. Collectively, throughout the fall semester SHAs amassed over 1,500 hours of training and team meetings, which frequently included continuing education. SHAs and IHE leads also attended monthly virtual "huddles" to share experiences and learn from clinical experts at MAHEC and UNCA as to how best continue supporting students, faculty, and staff and receive up-to-date COVID-19 information. Three huddles were offered during the semester about the following: 1) SHA successes, challenges and current activities in September, 2) IHE leadership gratitude, project highlights, and new COVID-19 education and Q\&A with MAHEC MDs in October, and 3) COVID19 trends and updates, an expert panel on safe campus exit and return, mental and emotional health, and tools for building resiliency in November.

The SHAs and program leads on all six campuses benefitted from IHE leadership, faculty, staff, and local health professional support. This support permitted SHA engagement in a wide range of on-campus and virtual activities that encouraged safer, healthier, and more resilient behaviors, including virtual and inperson support stations, witnessing wellness walks, social media promoted mask wearing contests, COVIDsafe emails and text alerts, decompression Zoom sessions, meal and care package deliveries to students in quarantine and isolation, virtual game nights, and influencer campaigns.

UNCA assembled an evaluation team to guide UNCA SHAs and support the other campuses in understanding the impact of this coordinated peer-education effort. The evaluation team led key stakeholders through an engaged evaluation process based on the Results-Based Accountability framework. The team worked to collectively identify and prioritize three categories of measures: how much did we do, how well did we do it, and is anyone better off? The team identified measures that were already being collected (e.g. confirmed COVID-19 cases on campus dashboards) and developed two surveys to capture other measures: evaluation of program impact on students attending in-person classes and on the SHAs themselves. WCU created their own evaluation methods which included post-wellness walk tracking by the SHAs and an in-person survey created and implemented by a graduate student team. The evaluation team reviewed these evaluation tools to identify seven performance measures used by both schools and shared these and the instruments with the four other campuses. Finally, each campus used data collected in the fall to plan for spring 2021.

\section{Project Descriptions at Three Campuses}

The practices and successes of this collaborative effort by six IHEs in WNC are highlighted in case study format for three of the six SHA programs. The 2020 time period includes March through May as a transition for all campuses to virtual learning, June and July as a preparation period for fall reopening of inperson classes, and August through December as the training and implementation period for SHAs on each of the IHEs.

\section{Mars Hill University (MHU)}

Mars Hill University (MHU) is a private, liberal arts institution located in Mars Hill, NC. In fall 2020, MHU had 1,051 enrolled students and 285 employees.

\section{The Program-The Healthy Lions Campaign}

The MHU SHA program was mobilized by five undergraduate students and one faculty lead. In midAugust, the SHA lead (Author) was selected for program lead at MHU and a SHA position description was posted on the student employee website. The following week, applications were reviewed and interviews were facilitated virtually over Zoom. By August $26^{\text {th }}$, five students had been hired as SHAs for approximately 10 hours a week each. These five students joined students from WWC, BC and MC in a 1/2 
day virtual SHA training in late August. The following week included their first weekly SHA meeting and two days assisting staff with student move-in.

These five SHAs contributed $\sim 400$ hours to the response effort during the fall semester. They assisted the MHU COVID-19 Response Team (CRT) with the implementation of new protocols and procedures, including: training students on the process for self-reporting temperature and symptoms, staffing various thermal camera temperature stations, delivering meals and care packages to students in quarantine and isolation, and promoting and assisting with multiple flu shot clinics held on campus.

In addition to reinforcement of public health education and messaging through social media platforms, the primary focus for programming was the Healthy Lions Campaign, a community influencer initiative "to keep our Lions safe, healthy, and on campus!" The campaign included a Healthy Lions Challenge, a reward system to encourage and support students who were demonstrating appropriate health behaviors and following COVID-19 guidelines. Students who met the established criteria were recognized as Healthy Lions Influencers and received a complimentary t-shirt. The SHAs also utilized the inherent leadership potential and high percentage of student-athletes (49\%) at MHU to extend the reach of the Healthy Lions Campaign. Two athletes per team were selected as Healthy Lions Influencers and served as liaisons between the athletic teams and the SHAs. The student-athletes helped to promote Healthy Lions programming and modeled healthy behaviors.

\section{Institutional and Environmental Support}

In August 2020, the MHU administration assembled 11 individuals to serve on the CRT. The SHA lead (Author) was part of the CRT and liaised with the CRT and SHAs. The CRT met daily throughout the semester to develop COVID-19 policies and procedures and to continually assess campus needs. Meetings and responsibilities consisted of reviewing new cases (housing needs, contacts, etc.), addressing academic support and communication with faculty regarding student navigation of classes from quarantine and isolation, coordinating room assignments and meal deliveries $(\sim 4,300$ meals were delivered by 40 faculty, staff, and SHAs). The CRT team also managed COVID-19 testing and contact tracing (by medical services and athletic training personnel), addressed concerns and policy violations generated from a community accountability form, updated university dashboard numbers, reviewed disaggregated data for forecasting, surveyed students in quarantine/isolation, and assisted with the reintegration plans for student-athletes and their teams. Campus-wide support included building a new Student Health Center in response to COVID19 and adding a part-time counselor to the staff. Face-to-face classes were also delayed three weeks, which enabled additional preparations to take place before student arrival.

Collaboration between SHAs and the CRT and the proactive approach to testing and contact tracing allowed the campus to continue with face-to-face learning. Across the fall semester there were 76 confirmed positive COVID-19 cases (65 students, 11 employees) for a student infection rate of $6.2 \%$ and an overall infection rate of $5.7 \%$. 


\section{FIGURE 1 \\ SHAS ASSISTING WITH FALL STUDENT CHECK-IN AND HANDING OUT PROMOTIONAL ITEMS (LEFT)}

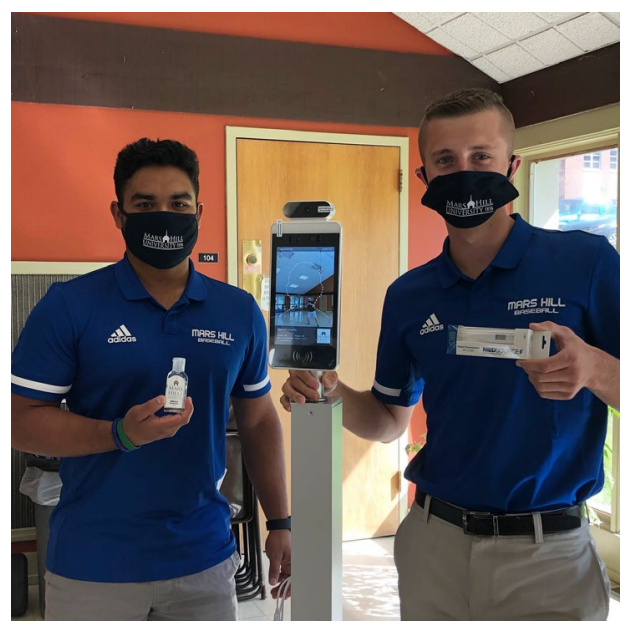

\section{Western Carolina University}

Western Carolina University (WCU) is a public regional comprehensive university in a rural area in WNC. WCU's student enrollment is over 12,000 with roughly 4,500 living on campus and a similar number living off-campus within a few miles of campus and it is one of the 17 UNC System institutions. WCU also has an additional 1,570 permanent full-time faculty and staff who are part of their campus population. A sustained commitment in partnership with the community is a hallmark of WCU and manifests in the form of engaged research, teaching, and service.

\section{Institutional Context}

Summer 2020 provided WCU administration and faculty the time to focus on planning for fall 2020 with the commitment to resuming in-person courses safely. Catamounts Care was the guiding policy for a safe, in-person reopen and was designed to remind our campus community of the shared standards and personal responsibility. The campaign focused on the following: proper hand washing, social and physical distancing, face coverings, cleaning/disinfecting, "Feeling sick? Stay home," self-care and respect and caring to all (WCU Community Standards, 2020). Catamounts Care included extensive messaging from campus leaders in the form of radio and social media ads, campus signage, and branded personal protective equipment packages for all faculty, staff, and students.

\section{The Program-The Catamounts Care Student Health Ambassadors Program}

Through the IHE partnership, the Catamounts Care SHA program was added to the WCU campaign. It focused specifically on outreach and education with the greater intention of fostering and supporting a culture of care around safe COVID-19 health-guidelines and practices. SHAs' primary goals centered on helping inform and educate student peers on COVID-19 health guidelines, positively reinforcing healthy COVID-19 behaviors and practices, and setting a positive example for peers. In late summer 2020, SHA position descriptions were developed and advertised, group interviews were facilitated, and an operational and logistics management structure was organized. By Monday, August $31^{\text {st }}$, the WCU SHA program had 21 ambassadors hired and trained. Each ambassador received a $\$ 1,300$ educational stipend.

The WCU SHA program was made up of three primary engagement components: witnessing wellness walks, sub-teams membership, and continuing education. Each of these strategies engaged SHAs, connected to one or more program goals, and was impact focused. During the fall semester (7/1/2012/31/20), WCU had 474 confirmed positive COVID-19 cases (437 students, 30 employees, and 7 contractors). During the fall, WCU's positivity rate never exceeded $13 \%$ and only twice exceeded $10 \%$ (the 
first two weeks back on campus, $8 / 21-8 / 31,12.8 \%$ and $13.2 \%$, respectively). A majority of the weeks (ten) reported a $<5 \%$ positive test result. This resulted in a $4.7 \%$ average infection rate across WCU students in fall 2020.

FIGURE 2

SHA TRAINING AT WCU

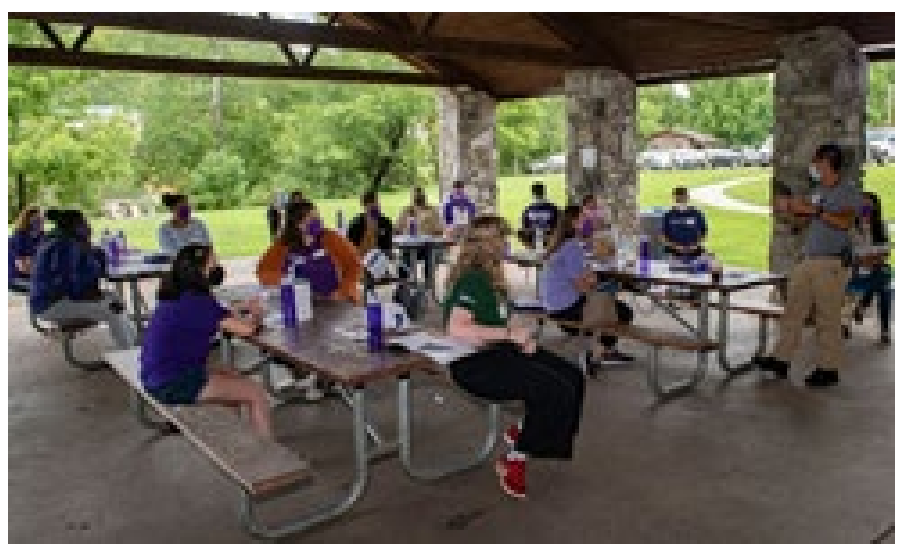

FIGURE 3

SHA IN ACTION AT WCU

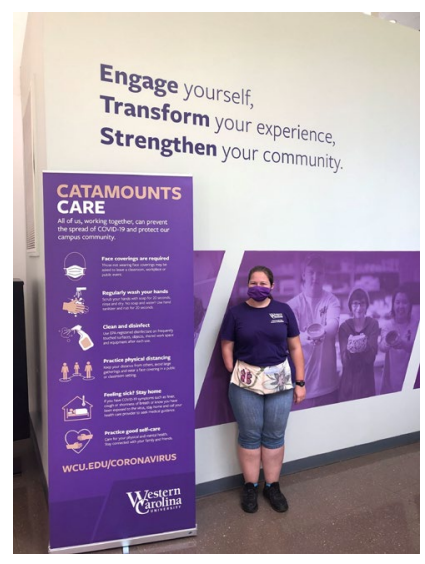

University of North Carolina - Asheville (UNCA)

University of North Carolina - Asheville (UNCA) is the state's designated public liberal arts university and one of 17 UNC System institutions. UNCA is located in Asheville, NC and had 3,363 enrolled students and 745 employees in fall 2020. UNCA's SHA program was developed in summer 2020 with a goal of reducing COVID-19 transmission and promoting wellness among students. The program included 45 paid SHAs (each paid \$12 an hour, working 5-15 hours per week), two staff leads (Author) and 9 faculty and staff advisors. Through the competitive hiring process, the leads looked for both formal and informal campus leaders who believed they could have a positive impact on their community. They also prioritized hiring Black, Indigenous, and People of Color-identified students due to racial disparities in COVID-19 infections, access to treatment, and job loss as a result of COVID-19. SHAs received 10 hours of initial training as well as continuing education and support through the semester. During fall 2020, SHAs provided 1,798 hours of in-person and virtual support through campus and Zoom support stations, planned or supported 32 events such as a Halloween scavenger hunt and voter registration and blood drives, and 
developed health promotion messages in collaboration with the office of Communication and Marketing. SHAs worked in teams such as Athletics, Performing Arts, Communications, and more.

\section{Institutional and Environmental Support}

Though the pandemic brought many challenges, UNCA faculty, staff, and administrators set the campus up for success. During summer 2020, Communication and Marketing led a working group of students, faculty, and staff to develop Expectations of Mutual Respect and Care for All as well as other return-tocampus guides and resources (UNCA Expectations of Mutual Respect and Care for All). Their office also provided two university-branded cloth masks and individual bottles of hand sanitizer to all students, faculty, and staff. The Director of Emergency Management led weekly planning meetings and consulted with administrators, providing ongoing opportunities for resource and information sharing. Residential Education ensured that students were spread into lower density housing and held over 90 campus spaces for students in need of quarantine or isolation, Academic Affairs shifted the academic calendar so the fall semester began (mid-August) and ended early (before Thanksgiving), and Campus Operations set up campus spaces to support social distancing and installed Plexiglass and sanitizing stations across campus. During the fall 2020 semester, $49 \%$ of classes were in-person, $33 \%$ were online, and $18 \%$ were a hybrid of in-person and online elements. Strong campus and community support for the SHA program was evident through frequent statements about the program from university administration, inclusion of the SHA lead in the Emergency Operations Committee, and offers of ongoing support for the program. All of these factors and many staff, faculty, and students contributed to this monumental effort to keep the campus community safe.

UNCA had only 36 confirmed COVID-19 cases among students and employees between July 1st and December 31st, 2020; this is the lowest prevalence of cases among the 17 campuses in the UNC System $(<1 \%$ infection rate for students and for students + employees). SHAs reported building leadership and communication skills, and feeling supported by faculty and staff. Additionally, UNCA was able to start classes as planned, stay on campus through the end of the semester, and offer exit testing for COVID-19 to any interested student. Campus quarantine and isolation spaces never reached capacity, and no COVID-19 cases were traced to classroom transmission. The majority of cases were traced to off campus sources.

FIGURE 4

\section{SHAS SUPPORTING CAMPUS RECREATION'S GLOWGA EVENT AT UNCA}

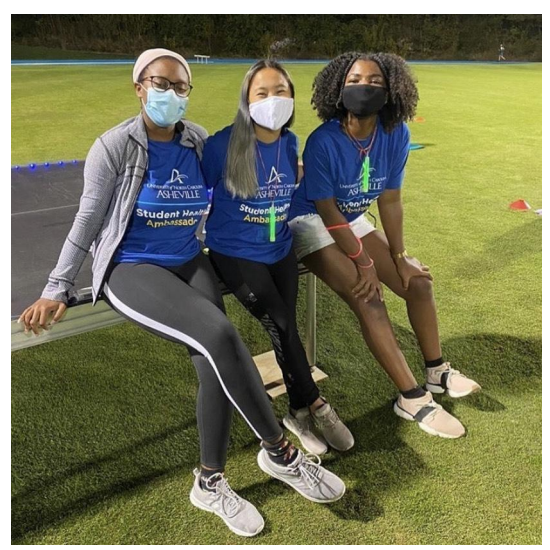




\section{FIGURE 5 \\ SHAS TABLING IN SUPPORT OF STUDENT MENTAL HEALTH AT UNCA}

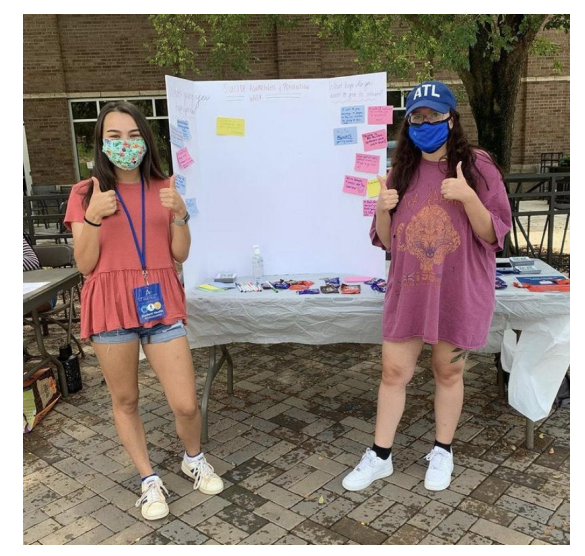

\section{DISCUSSION}

As highlighted by the experience of the three campuses detailed above, two key goals were realized by this IHE collaboration: 1) COVID-19 infection rates were mitigated by comprehensive prevention efforts and 2) students were able to live, learn, and play on campus for all or the majority of the term (some campuses had classes post-Thanksgiving that were shifted entirely online). Comprehensive prevention efforts included mandatory mask wearing, consistent social distancing practices in buildings, classrooms, living spaces and even outdoors, and frequent and thorough personal hand and surface disinfection. The collaborative SHA programs at each of these campuses supported the diffusion and adoption of these comprehensive prevention efforts.

Within higher education contexts, student leaders and their engagement are imperative. Deep impact is possible if practitioners can find ways to engage students in high-level roles. This assertion is supported in Rogers' Diffusion of Innovation theory and was concretely observed on these three campuses as SHAs were able to successfully diffuse healthy behaviors proven to slow the spread of COVID-19 in communities. With this, engaged, committed students are the keystones to ideas and behaviors diffusing across a campus. Engagement initiatives designed to slow viral spread require student buy-in which is more likely with peer modeling. This process is scalable and transferable, but it must start with dedicated and prepared student leaders who essentially serve as innovators and early adopters of ideas worth spreading.

Overall, regular communication between campus leaders, MAHEC, and SHAs amplified learning and created efficiencies of effort (or at least reduced duplication) and facilitated a shared culture of health and safety for the six IHEs in WNC. 
TABLE 1

FROM ENGAGEMENT ACTIVITIES TO IMPACT:

AN OVERVIEW OF SHA PROGRAMS AT 3 IHES

Activity (\# people)

Description

Impact

Goal 1: Model and positively reinforce healthy COVID-19 behaviors and practices.

\begin{tabular}{|c|c|c|}
\hline $\begin{array}{l}\text { MHU--Healthy } \\
\text { Lions Campaign } \\
\text { (5 SHAs and } 32 \\
\text { Healthy Lions } \\
\text { Influencers) }\end{array}$ & $\begin{array}{l}\text { Healthy Lions support table (1-2 hours/week) } \\
\text { Promotion of the Healthy Lions Campaign } \\
\text { Healthy Lions Challenge: a reward system to } \\
\text { encourage students to demonstrate appropriate } \\
\text { health behaviors and follow COVID-19 } \\
\text { guidelines. } \\
\text { SHAs "recruited" Healthy Lions Influencers ( } 2 \\
\text { from each athletic team) to model safe and } \\
\text { healthy behavior. }\end{array}$ & $\begin{array}{l}\text { Over } 350+\text { stamps and } 45 \text { t- } \\
\text { shirts were given out to } \\
\text { students by SHAs and } \\
\text { Healthy Lions Influencers. }\end{array}$ \\
\hline $\begin{array}{l}\text { WCU-- } \\
\text { Witnessing } \\
\text { Wellness Walks } \\
\text { (WWW) \& } \\
\text { Follow-Up Shift } \\
\text { Surveys (20 } \\
\text { SHAs) }\end{array}$ & $\begin{array}{l}\text { Organized daily (M-F, 2-hour shifts between } 9 \\
\text { am-5 pm) campus walks across three zones in } \\
\text { teams of two ( } 2-3 \text { shifts per week per SHA). } \\
\text { SHAs positively reinforced mask wearing, } \\
\text { physical distancing, and other positive behavior } \\
\text { with Catamounts Care stickers \& info bags. }\end{array}$ & $\begin{array}{l}\text { A total of } 422 \text { WWW's } \\
\text { over } 12 \text { weeks with } \sim 5,500 \\
\text { positive interactions and } \\
\sim 800 \text { challenging } \\
\text { interactions; distribution of } \\
\sim 4,000 \text { positive } \\
\text { reinforcement stickers \& } \\
\text { info bags. }\end{array}$ \\
\hline $\begin{array}{l}\text { WCU--Sub- } \\
\text { Team } \\
\text { Membership: } \\
\text { Incentives \& } \\
\text { Programming (7) }\end{array}$ & $\begin{array}{l}\text { Developed the weekly }(\mathrm{W}, 10 \text { am-1 pm) SHA } \\
\text { store where students could convert Catamounts } \\
\text { Care stickers into prizes (e.g., free coffee, t- } \\
\text { shirts, etc.), earn additional stickers, and get } \\
\text { info. }\end{array}$ & $\begin{array}{l}\text { Over } 10 \text { store weeks } \sim 50 \\
\text { customers per week } \\
\text { engaging a total of } \sim 500 \\
\text { student customers. }\end{array}$ \\
\hline
\end{tabular}

Goal 2: Educate and support other students in engaging in safer practices.

MHU Events (5 Supported events including student move in, SHAs)

UNCA--Support

stations - on

campus and

virtual (45 SHAs) staffing of thermal camera temperature

stations, multiple Flu Shot Clinics, the

Centennial of 19th Amendment - Women's

Right to Vote event.

Planned and facilitated a Tie Dye Mask

Decorating event for Halloween and a "Holiday

Workout" for students to do over the winter break.

Available 1-2 hour shifts each day of the week (fewer on Saturday and Sunday) in 4-8 campus locations.

Hosted 2 weekly virtual sessions (more on

weeks with high levels of need).

Provided voluntary temperature checks.
The SHAs organized and/or supported 15 events on campus in the fall semester.

1,798 support hours

provided in fall 2020 
UNCA Events

(45 SHAs)
Supported events organized by others such as supporting a Black Lives Matter protest and mural and Glowga by providing staffing and safer practices.

Planned and facilitated events such as a Halloween scavenger hunt open to pods and wellness bingo.
32 events planned, facilitated and/or supported

Goal 3: Inform and educate student peers on COVID-19 health guidelines. Develop social media and print health communication campaigns for other students.

\begin{tabular}{|c|c|c|}
\hline $\begin{array}{l}\text { MHU-- } \\
\text { Communications } \\
\text { \& Messaging (5 } \\
\text { SHAs) }\end{array}$ & $\begin{array}{l}\text { Developed and maintained Facebook, } \\
\text { Instagram, Twitter and email accounts. } \\
\text { Co-created and distributed informational flyers } \\
\text { related to COVID-19 and campus policies. } \\
\text { Promoted the MyReason WNC campaign } \\
\text { through posts and videos. }\end{array}$ & $\begin{array}{l}\text { For the 14-week fall } 2020 \\
\text { semester, over } 150 \text { posts } \\
\text { were made amongst the } 3 \\
\text { social media sites. } \\
\text { Followers: Facebook (99), } \\
\text { Instagram (202), Twitter } \\
\text { (32). }\end{array}$ \\
\hline $\begin{array}{l}\text { WCU--Sub- } \\
\text { Team } \\
\text { Membership: } \\
\text { Social Media (6 } \\
\text { SHAs) }\end{array}$ & $\begin{array}{l}\text { Developed and managed the SHA social media } \\
\text { account with the purpose of disseminating up- } \\
\text { to-date information. } \\
\text { Organized weekly posts \& campaigns focused } \\
\text { on campus guidelines and programs. }\end{array}$ & $\begin{array}{l}125 \text { Instagram followers, } 31 \\
\text { posts over the fall } 2020 \\
\text { semester, \& } 2-3 \text { weekly } \\
\text { stories. }\end{array}$ \\
\hline $\begin{array}{l}\text { UNCA-- } \\
\text { Communications } \\
\text { Team: SHAC } \\
\text { (one of eight } \\
\text { topic-based } \\
\text { teams); (6 SHAs, } \\
3 \text { advisors) }\end{array}$ & $\begin{array}{l}\text { Created and maintained an Instagram page } \\
\text { and email address. } \\
\text { Created and distributed print and digital flyers. } \\
\text { Managed communication between the } 8 \text { teams, } \\
\text { interested campus partners and students, and } \\
\text { worked directly with the university's } \\
\text { Communication and Marketing professionals. } \\
\text { Worked with campus and community } \\
\text { journalists. } \\
\text { Provided resources to the other IHEs. }\end{array}$ & $\begin{array}{l}317 \text { Instagram followers } \\
5 \text { videos produced in } \\
\text { collaboration with } \\
\text { Communication and } \\
\text { Marketing } \\
\text { Over } 30 \text { campus and } \\
\text { external publications }\end{array}$ \\
\hline
\end{tabular}

Goal 4: Support students in isolation or quarantine by helping to meet non-medical needs like meal or class supply delivery and virtual support and providing outreach and care to peers.

MHU--Support of students in Q\&I (5 SHAs)

WCU--Sub-

Team

Membership:

Outreach \& Care

(7 SHAs)
Coordinated meal delivery with faculty and staff volunteers to students in Q\&I.

Provided support for these students through distribution of goodie bags (crossword puzzles, candy, stress reliever items).

Developed the outreach effort to the Q\&I hall. Developed and implemented Thank You \& Pen Pal campaigns.
Over 4300 meals delivered to students in Q\&I over the semester by SHA's and 40 faculty/staff

150 Catamounts Care bags distributed, and distributed 100's of signed thank you cards to frontline employees and had 12 pen pals 
UNCA--Support of students in $\mathbf{Q}$

\& I (5 SHAs, 1 advisor)
SHAs worked with professional staff and Dining Services providers to coordinate meal delivery to students in Q\&I. Provided support through texts, phone calls, direct messages, and educational materials.

1,101 meals delivered

\title{
1,101 meals delivered
}

\author{
(1)
}

Goal 5: Participate in training to understand COVID-19, its impact, its prevention, and campus resources and engage in safer practices including the $3 \mathrm{Ws}$.

\begin{tabular}{|c|c|c|}
\hline $\begin{array}{l}\text { MHU--Training } \\
\text { and Continuing } \\
\text { Education (5 } \\
\text { SHAs) }\end{array}$ & $\begin{array}{l}\text { Received } 4 \text { hours of general training from the } \\
\text { leads and MAHEC partners in August. } \\
\text { Met weekly to discuss upcoming events and } \\
\text { updated COVID-19 information (e.g., case } \\
\text { rates, interventions, weekly reflections, etc.). } \\
\text { Met monthly for professional development with } \\
\text { all } 93 \text { SHAs from across the six IHEs. }\end{array}$ & $\begin{array}{l}12 \text { team meetings with the } \\
\text { SHA lead and } 4 \text { joint } \\
\text { meetings with all six } \\
\text { campus partners and } \\
\text { MAHEC }\end{array}$ \\
\hline $\begin{array}{l}\text { WCU--Training } \\
\text { and Continuing } \\
\text { Education (20 } \\
\text { SHAs) }\end{array}$ & $\begin{array}{l}\text { Met weekly to discuss updated COVID-19 } \\
\text { information (e.g., case rates, interventions, } \\
\text { weekly reflections, etc.) } \\
\text { Met monthly for professional development with } \\
\text { all } 93 \text { SHAs from across the six IHEs. }\end{array}$ & $\begin{array}{l}12 \text { continuing education } \\
\text { meetings with } 4 \text { as joint } \\
\text { meetings with all six } \\
\text { campus partners and } \\
\text { MAHEC }\end{array}$ \\
\hline $\begin{array}{l}\text { UNCA--Training } \\
\text { and Continuing } \\
\text { Education (45 } \\
\text { SHAs) }\end{array}$ & $\begin{array}{l}\text { SHAs received } 8 \text { hours of general training from } \\
\text { the leads and MAHEC in addition to } 2 \text { hours of } \\
\text { team content training in August. } \\
\text { Met weekly to discuss updated COVID } \\
\text { information (e.g., case rates, interventions, } \\
\text { weekly reflections, etc.). } \\
\text { Met monthly for professional development with } \\
\text { all } 93 \text { SHAs from across the six IHEs. }\end{array}$ & $\begin{array}{l}\text { Each SHA participated in } \\
\text { at a minimum of } 40 \text { hours } \\
\text { of meetings and trainings } \\
\text { through the } 15 \text {-week } \\
\text { semester }\end{array}$ \\
\hline
\end{tabular}

\section{Promising \& Transferable Practices}

A promising practice is a transferable concept that can be adopted and applied in other higher education contexts. As students were key to the Catamounts Care public health campaign, the Healthy Lions Campaign and the UNCA SHA program, the promising practices observed will be focused on the student perspective.

The first shared promising practice was identifying and selecting the right students. A common theme across all 21 of the ambassadors at WCU was their shared perspective that WCU was their home and that they wanted to do everything possible to keep their home and neighbors safe.

As leads recruited and interviewed possible SHAs at UNCA, they sought students who were well known on campus either as formal leaders (such as Student Government officers or athletic team captains) or informal leaders (students with many connections or who were simply well known on campus). They sought students who were positive, believed they could make an impact, were willing to be flexible in the face of changing guidance and institutional practices, and who were interested in health promotion but did not consider themselves experts. Key to peer education is building trust and peer educators must be willing to say, "I don't know but let me find out and get back to you."

At MHU, the lead looked for students who had demonstrated a passion for service, a level of commitment to, and prior involvement with, the campus community. Ideally, SHAs would be selfmotivated students with inherent leadership abilities, a strong work ethic and a sociable demeanor. The 
student-athletes selected as the first sub-group of Healthy Lions Influencers were deemed influential leaders due to their involvement in athletics, and could be utilized as early adopters (Rogers, 2003) in the facilitation of appropriate health behaviors on campus.

A second promising practice was strong institutional support, which at WCU came in the form of institutional messaging and administrative support (e.g., training welcome from the Chancellor, follow-up thank you notes, invitation to present at the board of trustees meeting, etc.). One SHA at WCU commented, "Even the chancellor took time out of her day to talk to the SHAs on their walks and tell them how proud of them she was." At UNCA, institutional support included the Chancellor's expressions of gratitude, grant support for the work, administrators highlighting SHA activities at campus wide town halls, and intensive support from Communication and Marketing, Health and Counseling, and other Student Affairs partners. The UNCA and WCU Chancellors also sent each of the SHAs a thank you gift and note at the end of the semester. The SHAs at MHU felt very supported by faculty and staff, and were acknowledged and thanked frequently and publicly by the Provost and University President, at Board of Trustees meetings, through Happenings on the Hill weekly updates, and in the Alumni \& Friends newsletter. MHU administration also provided financial resources to purchase prizes and incentives for the Healthy Lions Challenge. One staff member conveyed his appreciation for the project by stating, "I just wanted to shoot you a quick message of gratitude and support for your efforts and dedication to helping keep MHU healthy during this pandemic. I hope you know how vital and appreciated you are, even if it doesn't always feel that way."

Focusing the SHA role around the 3 Ps: positive, proactive, and prevention-focused was the third promising practice. Positive approaches included gain-framed health communication such as stickers for healthful behaviors witnessed on campuses and framing messages as "here is what you can do" rather than "here is what you cannot do." Similar positive reinforcement was demonstrated at MHU during the Healthy Lions Challenge and through the stamps given to students for appropriate health behaviors, (completing the Lion's Pledge to Pride, logging their daily temperatures/symptoms, and consistently practicing the $3 \mathrm{Ws}$ ). Much of UNCA's messaging was also gain-framed around safe activity choices. An SHA reflected, "Do not underestimate the power a sticker can have on making someone smile." Proactive approaches included producing videos for peers on how to prevent potential problems, hosting campus support stations, and organizing events to highlight the need for racial equity. The prevention focus was manifested through hosting events to promote mental and emotional health, supporting flu shot clinics, providing remote personal training to students in quarantine or isolation. A MHU SHA noted, "Helping at the flu shot clinic led to staff/faculty thanking the SHAs for helping students fill out insurance paperwork, which made me remember that our community is grateful for the effort we're making to stay healthy." As a second example, UNCA SHAs hosted a COVID-19 anxiety/mental health awareness event and, noting its impact, one student said they "connected with the SHAs over learning what aromatherapy can do to improve/stabilize moods, especially while living on campus during COVID."

To facilitate trust-building and sustained relationships with peers, enforcement roles were avoided due to the likelihood that a student chastised by a peer educator for improper mask wearing would not return to that peer educator for support in the future. UNCA's SHAs reported receiving lots of texts, direct messages, and questions during their classes from peers (and faculty) who respected them and knew they would get a non-judgmental, accurate response.

The fourth promising practice is focused on the leadership skills the ambassadors developed. Across all the campuses, SHA leads provided ongoing support and training for the SHAs so they had the skills and knowledge needed to develop as leaders, educate with confidence, and build trust with their peers. Ambassadors specifically noted they became active leaders and learned to make a positive difference in their community. In discussing the vital role of the SHAs, the MHU President acknowledged, "the students in the participating universities have begun to get some national recognition. Their jobs come with an enormous responsibility and they were a big part of our success last semester. I hope that every ambassador takes great pride in this accomplishment." The lessons SHAs learned on how to shape their WCU home was transferable to informing future environments and communities. One SHA stated "at a minimum, we helped the vibe on campus and at a maximum we directly helped our community stay [on campus in person]. You cannot underestimate the power of the vibe we helped create." Another WCU ambassador remarked 
similarly, "serving as a SHA has allowed me to continue to promote a culture of love, education, and respect, rather than hate, on our beautiful campus, with our beautiful people." This is a powerful belief about the world for student leaders to develop.

A fifth and overarching promising practice was the emphasis on peer-led campus culture change. SHA leads set this intention early and worked with SHAs to envision what that would look like in practice. At MHU, the SHAs started to realize their impact when peers and teammates asked questions such as, "what should I do if my roommate has a fever?" They also compared their ambassador role to that of "being on a team working towards a common goal...with communication as the foundational component for effective teamwork." Many SHAs made civic engagement a priority and worked collectively to overcome the "negative stigma surrounding us, COVID, etc." A UNCA SHA explained that our events "don't always have to be about COVID. We are fostering community, and talking to students about the election and other campus threats can be more important for the health of BIPOC students."

Student peers at WCU, stated that their SHAs "set a good example," hearing "affirmations make[s] me want to try more," and "make[s] me think of wearing a mask outside as well as inside." In their team meetings, SHAs highlighted the importance of the informal conversations and connections in shifting culture. They talked about how friends, people who live in their buildings, off-campus community members and even family would ask them about prevention strategies, testing, and for informal advice. They spoke eloquently about their roles to "influence happiness and help push forward a community in an uncertain time" and "to positively encourage students to follow university guidelines (three Ws) and to be a motivator for students across campus without being authoritative." Nearly $85 \%$ of the ambassador's peers (general students) at WCU surveyed reported a positive experience with the SHAs. The students' flexibility and adaptability was evident in their anticipation that most of their work would happen informally through texts, direct messages and conversations with peers, the coordinators prepared the SHAs to respond to questions accurately and without judgement.

In addition to shared successes, the three IHEs also experienced shared challenges. Leaders spoke often of "building the ship as we sail it" to communicate the necessity of rapid adaptation to emerging information and institutional mandates. Though this afforded the institutions flexibility in planning, leads were not able to be as intentional about evaluation of the SHA program as would have been ideal. Due to the emergent nature of the pandemic, evaluation of this program was conducted later in the semester and inconsistently across the institutions. Campus stakeholders describing this program at conference presentations understandably wanted to see evaluation results and they were admittedly limited.

A final shared challenge is envisioning sustained culture change and continued support of the program without external grant funding. After the pandemic ebbs, the hope is to maintain the incredible momentum achieved in a short period of time. The leads are hopeful that these promising practices can persist beyond the scope of this project and well after grant funding has expired.

\section{CONCLUSIONS}

The promising practices gleaned from these programs are transferable to other campuses who are interested in slowing the spread of COVID-19. Additionally, envisioning a post-COVID-19 campus, it is vital to recognize the value of gain-framing, peer-to-peer engagement, and the diffusion of positive ideas across campus through motivated and empowered students. Whether the message being relayed is focused on slowing the spread of COVID-19 or centered on responsible drinking, consent, or receiving the flu shot, messaging that is informed and diffused by students for students is a practice that can benefit whole campus communities.

Finally, these programs sought to fight fear with knowledge, research, and engagement. The more informed and engaged campus community members are, the more likely positive behaviors and actions will

beget more positive behaviors and actions. These programs were a key ingredient to the culture of care that was established to mitigate the spread of COVID-19 in fall 2020 across six campuses representing over 17,000 students across the WNC region. Furthermore, the implications of the promising practices offered here are also useful and relevant in a post-COVID-19 university campus environment. 


\section{REFERENCES}

Brack, A.B., Millard, M., \& Shah, K. (2008). Are peer educators really peers? Journal of American College Health, 56(5), 566-568. doi:10.3200/jach.56.5.566-568

CIDRAP. (2020). COVID-19 Higher Education. Retrieved January 15, 2021, from https://www.cidrap.umn.edu/covid-19/higher-education

Gallagher, K.M., \& Updegraff, J.A. (2011). Health message framing effects on attitudes, intentions, and behavior: A meta-analytic review. Annals of Behavioral Medicine, 43(1), 101-116. doi:10.1007/s12160-011-9308-7

Levy, K., \& Kilgour, L. (2020, August 12). Don't make college kids the coronavirus police. The New York Times. Retrieved January 15, 2021, from https://www.nytimes.com/2020/08/12/opinion/coronavirus-college-reopening.html

Losina, E., Leifer, V., Millham, L., Panella, C., Hyle, E., Mohareb, A., . . Freedberg, K. (2020). College campuses and COVID-19 mitigation: Clinical and economic value. Annals of Internal Medicine. doi:https://doi.org/10.7326/M20-6558

Mars Hill University. (n.d.). Profile of the 2020-21 Student Body. Retrieved from https://www.mhu.edu/about/profile-student-body/

O'steen B., \& Perry, L. (2012). Service-learning as a responsive and engaging curriculum: A higher education institution's response to natural disaster. Curriculum Matters, 8, 171-186. doi: $10.18296 / \mathrm{cm} .0144$

Rogers, E.M. (2003). Diffusion of Innovations (4th ed.). New York, New York: Free Press. Doi:0029266718

St. Amour, M. (2020, August 21). Colleges point fingers at students for partying, spreading COVID-19. Inside Higher Ed. Retrieved from https://www.insidehighered.com/news/2020/08/21/collegespoint-fingers-students-partying-spreading-covid-19. Accessed January 15, 2021.

University of North Carolina Asheville. (2020, November 20). Our Mission \& Vision. Retrieved from https://www.unca.edu/about/mission-values/

University of North Carolina Asheville. (n.d.). Community Expectations. Retrieved from https://coronavirus.unca.edu/return-to-campus/community-expectations/

Walke H.T., Honein, M.A., \& Redfield, R.R. (2020). Preventing and responding to COVID-19 on college campuses. JAMA, 324(17), 1727. doi:10.1001/jama.2020.20027

Western Carolina University. (2021, February 28). About Western Carolina. Retrieved from https://www.wcu.edu/discover/index.aspx

Western Carolina University. (2021, November 21). Community Standards. Retrieved from https://www.wcu.edu/operations-procedures/community-standards.aspx

White, S., Park, Y.S., Israel, T., \& Cordero, E.D. (2009). Longitudinal evaluation of peer health education on a college campus: Impact on health behaviors. Journal of American College Health, 57(5), 497-506. doi:10.3200/jach.57.5.497-506

Yan, Z., Finn, K., Cardinal, B.J., \& Bent, L. (2014). Promoting health behaviors using peer education: A demonstration project between international and American college students. American Journal of Health Education, 45(5), 288-296. doi:10.1080/19325037.2014.932727 